Available online at GSC Online Press Directory

GSC Biological and Pharmaceutical Sciences

e-ISSN: 2581-3250, CODEN (USA): GBPSC2

Journal homepage: https://www.gsconlinepress.com/journals/gscbps

(REVIEW ARTICLE)

\title{
Emergence, existence and distribution of foot and mouth disease in Pakistan in comparison with the global perspective
}

\author{
Sajid Sanaullah ${ }^{1,}{ }^{*}$, Rahman Sajjad Ur ${ }^{1}$, Nayab Sehrish ${ }^{1}$ and Khan Irfan Ullah ${ }^{2}$ \\ ${ }^{1}$ Institute of Microbiology, Faculty of Veterinary Science, University of Agriculture Faisalabad, Pakistan. \\ ${ }_{2}^{2}$ Nuclear Institute for Agriculture and Biology, Faisalabad, Pakistan.
}

Publication history: Received on 24 March 2019; revised on 21 April 2019; accepted on 24 April 2019

Article DOI: https://doi.org/10.30574/gscbps.2019.7.1.0045

\begin{abstract}
Foot and mouth disease (FMD) is an illness of cloven-footed animals which is highly contagious disease of goat, cattle, buffalo and sheep. FMD cause huge financial losses, particularly in underdeveloped countries. FMD has long-term effects like loss of productivity and restriction to trade. A virus called FMDV that belongs to Picornaviridae family is the causative agent of disease. FMD Virus (Aphthovirus) has seven serotypes named as Asia 1, SAT 1, SAT 2, SAT 3, A, C and 0 and 80 to 88 subtypes. There is no cross-protection and disease control is difficult due to continuous mutation. The developed countries have eradicated the disease but Pakistan is still suffering great economic losses due to lack of proper management, awareness and poor disease reporting. This review focuses on the emergence, existence and distribution of FMDV in Pakistan in comparison with the global perspective. All these factors are much important to know before we can formulate any control strategy for FMD on the national level. This paper reviews the FMD situation in Pakistan, its influence at present, future aspects of FMD disease and its economic impact.
\end{abstract}

Keywords: Cross Protection; Distribution; FMDV; Mutation; Prevention; Vaccination

\section{Introduction}

Foot and mouth disease (FMD) is a contagious disease of both domestic and wild cloven-footed animals. Main clinic signs of disease are very high fever up to $104^{\circ} \mathrm{C}$ that remains six to seven days. Important signs of disease include blisters on feet and inside the mouth that later ruptures causing lameness and restrain animals from eating and chewing. A virus known as FMDV, which is single stranded RNA virus, belongs to Picornaviridae, causes the disease. Incubation period consists of 1 to 12 days. The virus has seven serotypes that cause foot and mouth disease in animals named as serotype; A which is common in parts of South America, Africa and Asia, $\mathrm{O}$ is common in Parts of Africa and Asia with recent reports in the UK and Western Europe, $C$ is commonly present in some areas of Brazil, Asia 1 is an Asian serotype, SAT 2 and SAT 1 (South African Territories) are present in Sub-Saharan Africa while SAT 3 is commonly present in Southern Africa [18,24].

FMD is a disease of concern regarding production loses throughout the globe and due to its wide host range (Cattle, Buffalo, Sheep, Goat, Pig, Deer and Bison) and rapid spread by aerosol transmission. Direct animal-to-animal contact, fomites, fodder, inanimate objects and transport vehicles are the source spread of the virus [7,17].

The primary site of infection is mucosa of the pharynx and the virus may also get entry through skin cuts and GIT that distribute via the lymphatic system therefore, vesicles develop in mouth, on feet, muzzle and teat, which rupture in 48 hours. FMDV sheds in milk and gets an opportunity to spread the virus from one cow to other via raw milk [4].

\footnotetext{
${ }^{*}$ Corresponding author

E-mail address: sanaullahsajid@gmail.com
} 


\section{History of FMD}

An Italian monk named Hieronymus Fracastorius in 1514 firstly described FMD in cattle. He observed that the infected animals refused the feed and saw the vesicles on feet and in the oral cavity. Now the disease is present all over the world where the animals are present. More than 100 countries are affected by this disease; however, most of the advanced countries have eradicated this disease. The USA had nine major outbreaks since 1870 and most devastating in 1914, that affected 170,000 animals and cost about 4.5 million dollars in eradication plan. In the UK during 1967, 442,000 animals were slaughtered due to FMD outbreak. In Taiwan during 1997, FMD infected 100\% swine herd due to which 3.8 million swine were destroyed leading to 6.9 million dollars loss. In UK, FMD serotype 0 pan-Asia strain resulted in 2,000 cases in 2001 [18].

China affected with serotype Asia-1 in 2005 and UK again in 2007 resulted in major economic loses. Japan and Korea in 2011 affected with serotype A in January then type 0 in April, that led to 3 million population loss including cattle and pig. FMD is a very common disease in Pakistan and its outbreaks are very usual. Most prevalent serotypes in Pakistan are type 0 which is around 70\%; type A around 4\% and Asia-1 is about 25\% [1].

In Pakistan, livestock sector shares $11.45 \%$ of total gross domestic production (GDP). Animal herds comprise of 26.3 million buffaloes and 24.2 million cattle. More than $30 \%$ rural population raising animals, having the household holding of 5-6 sheep/goat and 2-3 cattle/buffaloes per family that help them fulfilling their family needs[15].

\section{Geography and climate of Pakistan}

Pakistan is a blend of landscapes having deserts, mountains, hills and forests. Pakistan overlaps with both India where Sindh and Punjab lie in Indian plate and Eurasia where Baluchistan and KPK lie in Eurasian plate. Pakistan shares borderline with India, China, Iran and Afghanistan. Pakistan is divided into 3 major divisions of Northern highlands and Indus river plain with 2 further subdivisions corresponding to provinces of Sindh and Punjab [15].

Pakistan lies in temperate zone, characterize by monsoon season with adequate rainfall up to 10 inches to 150 inches per year particularly in Punjab province. Pakistan enjoys four seasons, a cool dry winter from December to February; dry, hot spring from March to May; summer rainy season and monsoon season from July to September; retreating monsoon season present in October and November [16].The probability of FMD in Punjab province is relatively high because the region has major animal trade route in Asia, linking India with Afghanistan, Middle East and Iran. Due to airborne spread and favorable season in Pakistan, FMD hits Pakistan badly. Moreover, increasing consumption of animal products in the region is progressively increasing the risk of FMD [13].

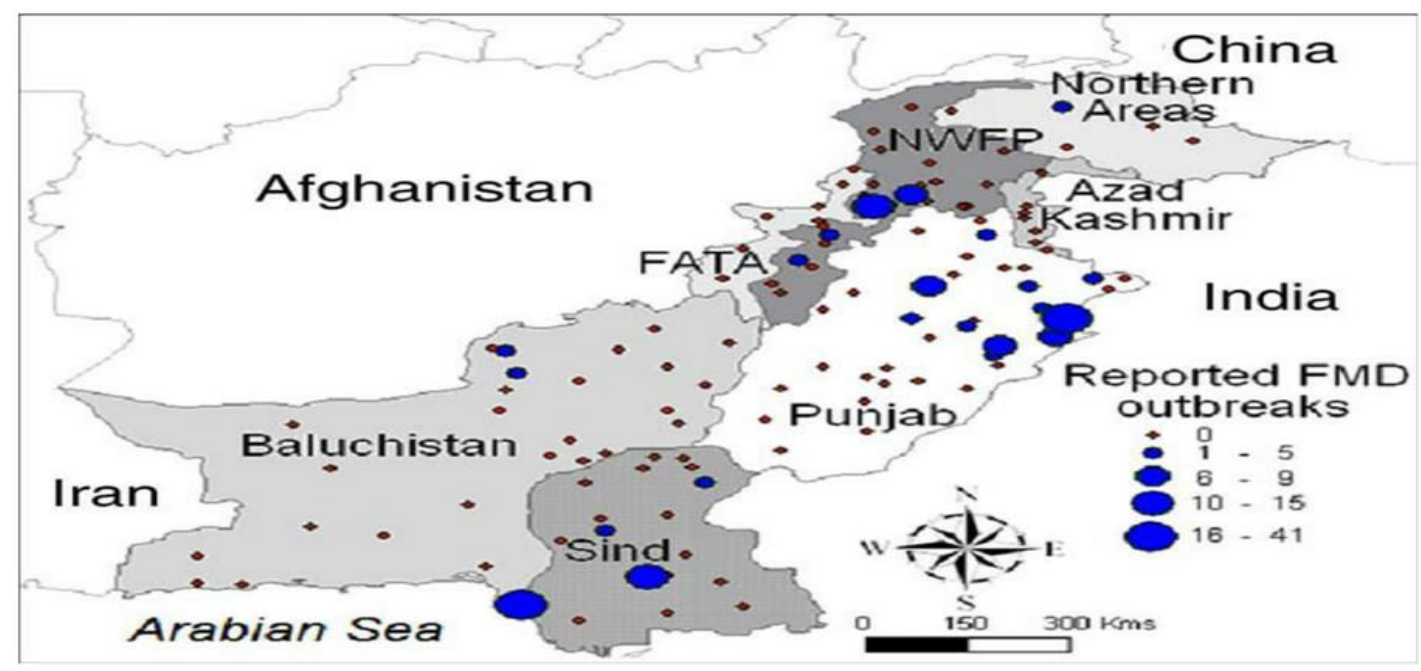

Figure 1 Spatial distribution of FMD in Pakistan using imperfect data 


\section{Importance of foot and mouth disease}

FMD disease has great economic importance considering the loss of milk production, infertility, incapacitation of draught animals, loss of meat products and young stock mortality. FMD affecting particularly buffalo, cattle, sheep and goat. Buffalo is the key animal regarding milk production in Pakistan and plays an important role in earning of people living in Pakistan. Buffaloes are kept mainly for milk production. Female animals got much attention as they are the basic source of earning through milk production and kept for breeding while males are kept for draught purposes and used in cultivation mainly in rural areas or slaughtered for meat. Goat meat is consumed here as an important human diet and sheep are kept for wool and mutton production. FMD disease is also vital in Pigs, which is prohibited on religious grounds in Pakistan [6].

\section{FMDV transmission}

FMDV is present in all excretions and secretions including saliva, urine, feces, expired air, milk, semen as well as amniotic fluid and vesicles that are FMD-associated. FMD virus spread through direct contact with infected animals; virus enters in susceptible host through abrasions, cuts and damaged epithelium. FMDV also transmit through physical contact with secretions containing a large amount of virus. Virus transmission can also take place through indirect route via fomites, contaminated water and feed. The most alarming thing about the virus is aerosol transmission from sick to healthy animals. Disease transmission also takes place through contaminated vehicles and persons working at farm. Under certain situations, FMD virus can travel to large distances. High humidity level usually up to $55 \%$ and air turbulence helps the virus in spread and distribution to long distances [2].

\section{FMD affecting different species of animals}

FMD show typical signs in different species of animals affecting the productive and reproductive efficiency of animals. FMD has a different impact on different species of animals.

\subsection{Cattle}

Cattle in highly productive animal all over the globe: especially in the developed countries. Cattle with FMD have different clinical signs as compared to other cloven-footed animals. Cattle develop febrile condition with lesions on dental pads, tongue, gums, muzzle, soft palate and nostrils.

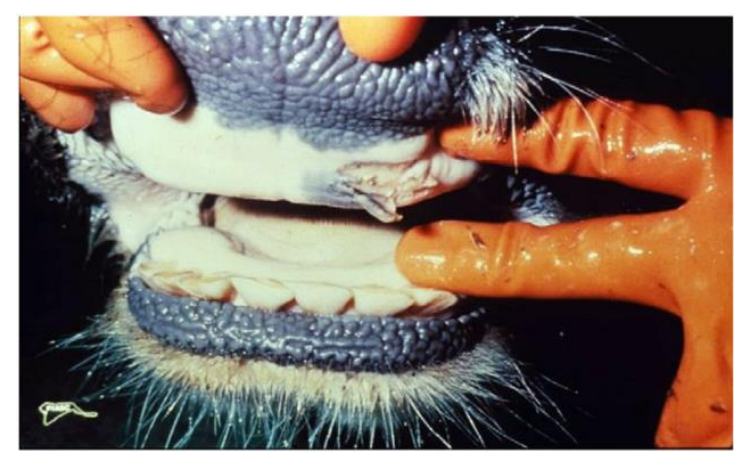

Figure 2 Ruptured oral blisters in diseased cow

Vesicles on tongue rupture quickly and tongue becomes painful, which restrain animal from eating and drinking. Nasal discharge and profuse salivation is often seen in cattle. Nasal discharge is mucoid at first and becomes mucopurulent later. The animal becomes lethargic and sudden drop in milk production takes place. In some cases, milk yield remains low in next lactation. Lesions can be seen on hoof in the area of interdigital space and coronary band. Other complications of FMD are mastitis and hoof malformation [13].

\subsection{Water Buffalo}

Foot and mouth lesions are seen in water buffalo but symptoms of the disease are milder in buffalo than cattle, also lesions heal faster and a study reported that foot lesions expected to occur on the bulb of the heel in buffalo than in interdigital space as in cattle [13]. 


\subsection{Sheep and Goat}

Mild cases appear in sheep and goat but FMD effects severely. Mostly animal is asymptomatic and lesions are only seen at one site. Common signs of disease are fever and lameness of one or more legs. Mouth lesions may appear as shallow erosions. Vesicles can be seen on teat but rarely on prepuce or vulva. Loss of milk production in females and rams affected with foot and mouth disease show the unwillingness to mate [13].

\subsection{Camelids}

Some reviews indicate that severe infection can occur in camelids but FMD virus might not be isolated and the majority of cases are unverified. On trial basis, infected Bactrian camel develops moderate to severe signs of disease with lesions seen on hind legs and exudates of footpad but no oral lesions. The detachment of sole has also been reported in camels due to FMD [23].

\subsection{Wildlife}

Clinical signs of FMD in wildlife are same as in domestic animals with erosions and lesions seen on foot and mouth. The severity of illness varies with species. Antelope and Impala are more susceptible to FMD virus. However, high mortality is seen in captive wild animals [10].

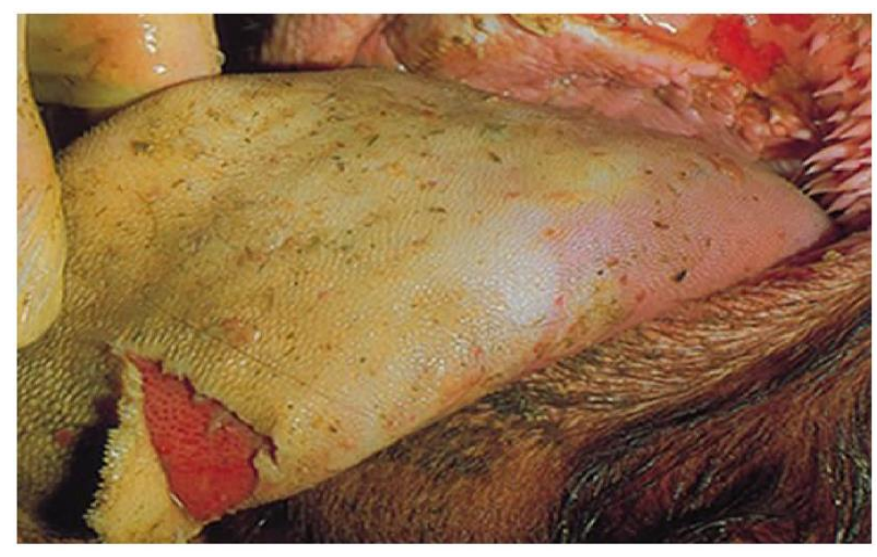

Figure 3 Two-day old lesions in the mouth of a steer

\section{Epidemiology}

Foot and Mouth disease virus affecting number of animals like buffalo, cattle, sheep, goat and wild ruminants. FMD virus is single-stranded RNA virus of family Picornavirus, genus Aphthovirus consisting of seven serotypes: Asia 1, A, C, O, SAT 2, SAT 1 and SAT 3. Foot and Mouth disease is prevalent in Pakistan and causes economic losses to buffalo and cattle particularly in commercial dairy farming. According to OIE report, Pakistan reported up to 10-30 outbreaks per year until the year 2000 after that no clear statistical data is present [9].

FMD has frequent outbreaks in Pakistan around the year. Most outbreaks were reported in Punjab province then Sindh followed by Balochistan and Northern areas. According to a study in Punjab, the highest prevalence was recorded in Sheikhupura district and lowest in Chakwal district [1].

According to farmer's conception, the frequency of FMD remains almost constant in all four seasons, $22.6 \%$ in winter, $20.5 \%$ in spring, $21 \%$ in summer and $23.9 \%$ in fall. Maximum outbreaks of FMD occur in Punjab, mainly due to large number of animal population and animal movement like animal markets held especially at Eid ul Azha festival playing important role in disease spread in Pakistan. FMD in Pakistan is also seasonal particularly in harvesting season in March-April and in September-October related to the movement of animals. Mild to sub clinical disease affect animals and recovery is possible in few days. The disease has changed its course due to high susceptible population and introduction of the exotic population. Now, this disease is present throughout the year and becoming more severe [1]. 


\section{Diagnostic tests}

Diagnostic tests for FMD vary with the purpose of test and stage of the disease. In cute cases, FMD virus can be isolated from the vesicular fluid, mouth secretions, epithelium and milk. Recommended sample collection site is epithelium from freshly ruptured or unruptured vesicle. Viral antigens are confirmed by Enzyme-Linked Immunosorbent Assay (ELISA), Nucleic acid with a Reverse Transcriptase-Polymerase Chain Reaction (RT-PCR) and Loop Mediated Isothermal Amplification (LAMP). However, Compliment Fixation Test (CFT) is still applicable in some countries [14].

\section{Impact of FMD}

FMD affect all species due to its high morbidity and low mortality rate.

\subsection{Direct impact}

\subsubsection{Visible losses}

Reduced milk production due to FMD, affects both humans and calves that depend on milk. Milk is important nutritional source also have an economical importance. Chronic FMD can decrease milk production up to $80 \%$. It also causes loss of traction power in draught animals especially during harvesting season in developing countries like Pakistan. FMD can result in abortion that has a negative impact on farm economy [19].

\subsubsection{Invisible losses}

Fertility problems due to abortion and poor conception rates are the invisible losses of FMD that a farmer faces. This invisible loss means that for every liter of milk and every kilogram of meat produced there is an extra fixed cost to sustain more stock [19].

\subsection{Indirect impact}

\subsubsection{Additional costs}

The control cost like vaccination, treatment, culling, compensation and outbreak control comes under additional cost. It is estimated that in the world every year about 2.35 billion doses of FMD are injected. FMD early detection and control is costly [3].

\subsubsection{Revenue foregone}

FMD infected countries are banned from accessing the market for trade with FMD free countries that results in the loss of revenue and profitability. Trade of FMD free livestock products resulting in 50\% more profit. Lack of market approach results in the loss of commercial farming and decrease in trade results in increase of prices for local consumers [3].

\section{Control of FMD}

\subsection{Disease reporting}

In order to avoid FMD losses, disease reporting is a very important factor. A veterinarian who suspects this disease should follow local or national guidelines to report FMD. Timely disease reporting plays a major role to avoid big losses.

\subsection{Prevention}

Controlling import can help to prevent the spread of FMD virus from endemic regions to the FMD free areas. Avoiding swill feeding, quarantine measures adoption and movement restrictions can reduce the chances of FMDV infection. Additionally, culling of infected animals and safe disposal of the carcass by incineration, rendering and burial can make the remaining herd disease free. Vaccination at specific periods and at proper time can make the animals immune to FMD virus during outbreaks $[11,12]$. 


\section{FMD movement control zones}

Table 1 OIE global foot and mouth disease control strategy

\begin{tabular}{|c|c|c|}
\hline Control Zones & $\begin{array}{l}\text { Movement control on susceptible } \\
\text { animals }\end{array}$ & $\begin{array}{l}\text { Condition for marketing meat and } \\
\text { milk }\end{array}$ \\
\hline $\begin{array}{l}\text { Temporary Control Zone (TCZ) } \\
\text { Around suspected premises } \\
\text { Controls can be placed on the } \\
\text { movement of vehicles, animal products, } \\
\text { people, things and non-susceptible } \\
\text { animals }\end{array}$ & $\begin{array}{l}\text { Ban on the movement of susceptible } \\
\text { animals in and out of TCZ } \\
\text { Stray susceptible animals can be } \\
\text { destroyed. }\end{array}$ & $\mathrm{N} / \mathrm{A}$ \\
\hline $\begin{array}{l}\text { Supplementary Control Zone (SCZ) } \\
\text { To prevent disease spread. } \\
\text { Can be used to control movement of } \\
\text { susceptible animals for } 72 \text { hours. }\end{array}$ & $\begin{array}{l}\text { Impose ban on the in and out movement } \\
\text { of animals in SCZ }\end{array}$ & $\mathrm{N} / \mathrm{A}$ \\
\hline $\begin{array}{l}\text { Restricted Zone (RZ) } \\
\text { After confirmation of FMD in animals } \\
\text { To prevent the disease spread in } \\
\text { animals }\end{array}$ & $\begin{array}{l}\text { Ban on the movement of susceptible } \\
\text { animals in and out of RZ except under } \\
\text { license. } \\
\text { Ban on animal gatherings. } \\
\text { Control on slaughtering of susceptible } \\
\text { animals. } \\
\text { Stray and feral susceptible animals can } \\
\text { be destroyed. }\end{array}$ & $\begin{array}{l}\text { N/A, Unless premises are within } \\
\text { another zone. }\end{array}$ \\
\hline $\begin{array}{l}\text { Protection Zone (PZ) } \\
\text { Around infected premises } \\
\text { Covers a minimum of } 3 \mathrm{~km} \text { radius to } \\
\text { control the disease }\end{array}$ & $\begin{array}{l}\text { Ban on the movement of animals in PZ } \\
\text { except: } \\
\text { Emergency slaughtering under license. } \\
\text { Ban on animal gathering } \\
\text { Ban on the movement of vehicles used in } \\
\text { the transport of animals } \\
\text { Ban on shearing. } \\
\text { Ban on the sale of hides and skin. }\end{array}$ & $\begin{array}{l}\text { Fresh meat can be transported if: } \\
\text { Treatment is applied before being } \\
\text { marketed } \\
\text { It was produced more than } 21 \text { days } \\
\text { before the earliest infection date } \\
\text { Milk produced by the animals in this } \\
\text { zone can be marketed if pasteurized. }\end{array}$ \\
\hline $\begin{array}{l}\text { Surveillance Zone (SZ) } \\
\text { Around a protected zone } \\
\text { That covers a minimum } 10 \mathrm{~km} \text { radius } \\
\text { from the infected premises }\end{array}$ & $\begin{array}{l}\text { Ban on the movement from premises. } \\
\text { Specific requirement to keep dogs and } \\
\text { poultry under control. } \\
\text { Ban on shearing and dipping except by } \\
\text { license. } \\
\text { Ban on sale of hides and skin of } \\
\text { susceptible animals. } \\
\text { Persons in charge of vehicles must } \\
\text { adhere to the required cleaning and } \\
\text { disinfection. } \\
\text { Controls for the collection, transport and } \\
\text { processing of raw milk }\end{array}$ & $\begin{array}{l}\text { Meat to be cooked } \\
\text { Milk to be pasteurized }\end{array}$ \\
\hline $\begin{array}{l}\text { Wild animal Infected Zone (WAIZ) } \\
\text { If disease is confirmed in wild animals. } \\
\text { To control disease spread } \\
\text { Susceptible animals must be separated }\end{array}$ & $\begin{array}{l}\text { Ban on the movement of wild animals in } \\
\text { and out of premises }\end{array}$ & $\mathrm{N} / \mathrm{A}$ \\
\hline
\end{tabular}




\section{Failure of FMD control in Pakistan}

In Pakistan many socio-economical and natural problems like lack of regular disease surveillance, no restriction on animal movements, public access to affected areas and long delays between the possible FMD outbreaks and confirmation of infection, made the control of FMD disease difficult [5].

FMD has different serotypes and sub serotypes, the frequent mutation within subtypes results in failure of FMD control. About 80 to 88 sub types have been identified globally which are immunologically and ontogenetically different and do not provide cross-protection. If the animal becomes immune against one subtype, remains susceptible to the other. Lack of comprehensive vaccination program is one of the major failures in controlling FMD. Lack of quarantine measures and nomadic animal movements are the other factors in FMD virus spread and the infection spread from one place to other. The most important thing is about 50\% of animals after recovery from FMD disease remains a carrier. In Pakistan, lack of communication between veterinarians and farmers; results in ignorance of FMD. Common water and feeding system and use of dirty utensils cause the spread of infection [15].

\section{Vaccination}

For effective control of FMD through vaccination, a coordination body (leadership) is lacking at the international level to keep an eye on the spread of this disease through different endemic regions. Along with this molecular characterization and vaccine matching studies are not a routine in different endemic countries, due to lack of trust, finance or technical expertise [8]. FMD virus goes under frequent mutations as described elsewhere in this document, due to which its control through vaccination is very difficult. These limitations lead to the reduction in the possibility of developing a unified methodology in near future.

In 2001, Great Britain's livestock industry faced an epidemic of FMD and lead to the movement restriction and biosafety measure at country level that resulted in the localization of the disease instead of long distance jumps. Intensive study and modeling were conducted in the outbreak area to reveal the mode of spread of disease in time and space $[16,20,22]$. All the models suggested rapid culling of the infected premises (IPs) and at-risk farms (contiguous premises, CPs and dangerous contacts, DCs) to control the disease instead of vaccination. In Pakistan, billions of rupees are being spent on vaccination i.e. for the year 2017 alone, Punjab government have spent 1.5 billion rupees on the import of FMD vaccine under Farmer Package Project for only four Districts

\section{Conclusion}

Despite considerable information on FMD Virus and vaccination still, FMD is the main threat to livestock in Pakistan. New emerging strains through mutation results in major outbreaks. Almost all the countries in the world that have gained FMD free status, achieved this through culling, animal movement restrictions, disease surveillance and biosafety measures at the country level instead of vaccination[21]. As culling of the animals is not feasible in Pakistan for eradication of the disease due to the economic situation, vaccination is the only hope to control its major epidemics. For this, ring vaccination (vaccination around the outbreak area), mass vaccination (carpet vaccination) and predictive vaccination (vaccination of the farms that can cause a future epidemic) are suggested strategies. Out of all the vaccination strategies, most effective is mass vaccination coupled with culling [1].Because only mass vaccination without culling lead to a significantly longer and larger epidemic. Out of all three vaccination strategies, predictive vaccination is proved to be most effective if culling is not feasible.

\section{Compliance with ethical standards}

\section{Acknowledgments}

I would like to thank Dr Mudasser Habib for his comments and advice. The excellent technical help from Dr Salah Ud din Shah is much appreciated.

\section{Disclosure of conflict of interest}

The authors declared that the work presented was not performed in the presence of any personal, professional or financial relationships that could potentially seen as a conflict of interest. 


\section{References}

[1] Abubakar M, Kanwal S, and Saeed A. (2012). Persistence, emergence and distribution of foot and mouth disease virus (FMDV); global and pakistan perspectives. Foot.

[2] Anjum R, Hussain M, Zahoor AB, IrshadH, and Farooq U. (2004). Epidemiological analyses of foot and mouth disease in Pakistan. Economic Survey, 5.

[3] Arzt J, Baxt B, GrubmanMJ, Jackson T, Juleff N, Rhyan J and Rodriguez LL. (2011). ThePathogenesis of Foot-andMouth Disease II: Viral Pathways in Swine, Small Ruminants, and Wildlife; Myotropism, Chronic Syndromes and MolecularVirus-HostInteractions. Transboundary and emerging diseases, 58(4), 305-326.

[4] Coetzer JAW, Thomson GR and TustinRC. (1994). Infectious diseases of livestock with special reference to Southern Africa.

[5] Ferguson NM, Donnelly CA and Anderson RM. (2001). The foot-and-mouth epidemic in Great Britain: pattern of spread and impact of interventions. Science, 292(5519), 1155-1160.

[6] Ferris NP, Donaldson AI, Shrestha RM and Kitching RP. (1992). A review of foot and mouth disease in Nepal. Revue scientifique et technique (International Office of Epizootics), 11(3), 685-698.

[7] Gibbens JC, Sharpe CE, Wilesmith JW, Mansley LM, Michalopoulou E, Ryan JB and HudsonM. (2001). Descriptive epidemiology of the 2001 foot-and-mouth disease epidemic in Great Britain: the first five months. The Veterinary Record, 149(24), 729-743.

[8] Grubman MJ and Baxt B. (2004). Foot-and-mouth disease. Clinical microbiology reviews, 17(2), 465-493.

[9] James AD and Rushton J. (2002). The economics of foot and mouth disease. Revue scientifique et technique-office international des epizooties, 21(3), 637-641.

[10] Keeling MJ, Woolhouse ME, Shaw DJ, Matthews L, Chase-Topping M, HaydonDT and Grenfell BT. (2001). Dynamics of the 2001 UK foot and mouth epidemic: stochastic dispersal in a heterogeneous landscape. Science, 294(5543), 813-817.

[11] Kitching RP. (2002). Clinical variation in foot and mouth disease: cattle. Revue scientifique et technique-Office international des epizooties, 21(3), 499-502.

[12] KitchingRP and Hughes GJ. (2002). Clinical variation in foot and mouth disease: sheep and goats. Revue Scientifique Et Technique-Office International Des Epizooties, 21(3), 505-510.

[13] Klein J, Hussain M, Ahmad M, Afzal M and Alexandersen S. (2008). Epidemiology of foot-and-mouth disease in Landhi Dairy Colony, Pakistan, the world largest Buffalo colony. Virology Journal, 5(1), 53.

[14] Leforban Y. (1999). Prevention measures against foot-and-mouth disease in Europe in recent years. Vaccine, 17(13), 1755-1759.

[15] Nawaz Z, Arshad M and Iqbal Z. (2014). Epidemiology of foot and mouth disease in buffaloes and cattle of Punjab using nonstructural proteins ELISA. Pakistan Journal of Agricultural Sciences, 51(2).

[16] NommanAM and Schmitz M. (2011). Economic assessment of the impact of climate change on the agriculture of Pakistan. Business and Economic Horizons, 4(1), 1-12.

[17] Morris RS, Wilesmith JW, Stern MW, SansonRL and Stevenson MA. (2001). Predictive spatial modelling of alternative control strategies for the foot-and-mouth disease epidemic in Great Britain, 2001. In II International Symposium on Application of Modelling as an Innovative Technology in the Agri-Food Chain; MODEL-IT 566(pp. 337-347).

[18] Mumtaz Z, Salway S, Nykiforuk C, Bhatti A, Ataullahjan A and Ayyalasomayajula B. (2013). The role of social geography on Lady Health Workers' mobility and effectiveness in Pakistan. Social science \& medicine, 91, 48-57.

[19] Paton DJ, Valarcher J, Bergmann I, Matlho OG, Zakharov VM, Palma EL and Thomson GR. (2005). Selection of foot and mouth disease vaccine strains-a review. Revue Scientifique Et Technique-Office International Des Epizooties, 24(3), 981.

[20] PattnaikB, Subramaniam S, Sanyal A, Mohapatra JK, Dash BB, Ranjan R and Rout M. (2012). Foot-and-mouth disease: global status and future road map for control and prevention in India. Agricultural Research, 1(2), 132147. 
[21] Reid SM, Grierson SS, Ferris NP, Hutchings GH and Alexandersen S. (2003). Evaluation of automated RT-PCR to accelerate the laboratory diagnosis of foot-and-mouth disease virus. Journal of virological methods, 107(2), 129139.

[22] Ster IC, Dodd PJ and Ferguson NM. (2012). Within-farm transmission dynamics of foot and mouth disease as revealed by the 2001 epidemic in Great Britain. Epidemics, 4(3), 158-169.

[23] [Wernery U andKinne J. (2012). Foot and mouth disease and similar virus infections in camelids: a review. Rev Sci Tech, 31(3), 907-918.

[24] Woolhouse M, Chase-Topping M, Haydon D, FriarJ, Matthews L, Hughes G and Keeling M. (2001). Epidemiology: foot-and-mouth disease under control in the UK. Nature, 411(6835), 258.

\section{How to cite this article}

Sajid S, Rahman SU, Nayab S and Khan I. (2019). Emergence, existence and distribution of foot and mouth disease in Pakistan in comparison with the global perspective. GSC Biological and Pharmaceutical Sciences, 7(1), 102-110. 